\title{
Jiří Pešek, Falk Wiesemann (dir.), Blut. Perspektiven in Medizin, Geschichte und Gesellschaft
}

Essen : Klartext (Veröffentlichungen zur Kultur und Geschichte im östlichen Europa, Bd. 38), 2011, 280 p., 29,95€

\section{Laurence Moulinier-Brogi}

\section{OpenEdition}

\section{Journals}

Édition électronique

URL : http://journals.openedition.org/ifha/8207

DOI : $10.4000 /$ ifha. 8207

ISSN : 2198-8943

\section{Éditeur}

IFRA - Institut franco-allemand (sciences historiques et sociales)

\section{Référence électronique}

Laurence Moulinier-Brogi, « Jiří Pešek, Falk Wiesemann (dir.), Blut. Perspektiven in Medizin, Geschichte und Gesellschaft », Revue de l'IFHA [En ligne], Date de recension, mis en ligne le 14 avril 2015, consulté le 22 septembre 2020. URL : http://journals.openedition.org/ifha/8207 ; DOI : https://doi.org/10.4000/ ifha.8207

Ce document a été généré automatiquement le 22 septembre 2020.

(CIFHA 


\title{
Jiří Pešek, Falk Wiesemann (dir.), Blut. Perspektiven in Medizin, Geschichte und Gesellschaft
}

\author{
Essen : Klartext (Veröffentlichungen zur Kultur und Geschichte im
}

östlichen Europa, Bd. 38), 2011, 280 p., 29,95€

\section{Laurence Moulinier-Brogi}

L'ouvrage dirigé par Jiř́ Pešek et Falk Wiesemann rassemble les actes de journées d'études interdisciplinaires organisées conjointement en 2009 par l'université Charles $\mathrm{V}$ de Prague et l'université Heinrich-Heine de Düsseldorf, et consacrées au sang à travers les âges, de l'Antiquité à nos jours, considéré au prisme de l'histoire de la médecine, mais aussi de l'histoire sociale, de l'histoire de l'art, et de celle des religions. Les 20 contributions rassemblées sont donc réparties en cinq principales sections : le sang dans l'Antiquité, le sang et l'histoire des images, le sang dans la recherche médicale, le sang comme objet de l'histoire des sciences, et le sang vu par différentes cultures, y compris hors d'Europe.

Le volume s'ouvre ainsi sur un premier ensemble de trois articles traitant du sang dans l'Antiquité. Les deux premiers articles traitent de la place du sang dans le monde égyptien du point de vue religieux et médical et permettent de comprendre la relation paradoxale du monde égyptien avec le sang. Le troisième article s'intéresse au sang animal dans le cadre du sacrifice rituel d'animaux, et particulièrement aux raisons multiples de l'abandon de cette pratique à la fin de l'Antiquité.

La section suivante a pour dénominateur commun la représentation du sang dans le monde chrétien, du Moyen Âge à nos jours. Les deux premiers articles s'intéressent à la représentation du sang dans le cadre du discours anti-juif, notamment dans les images relayant cette propagande, et aux différentes accusations lancées contre les communautés juives, qui sont pour la plupart à mettre en lien avec la question de l'utilisation du sang dans certains rites juifs. L'article suivant traite de l'utilisation de la couleur rouge et du sang dans la peinture et met en relation le travail de l'actionniste viennois Hermann Nitsch et celui du peintre Eugène Delacroix. Le troisième ensemble 
relève davantage de l'histoire de la médecine et traite notamment des découvertes permises par une meilleure compréhension des différents composants du sang; les quatrième et cinquième sections, pour leur part, traitent davantage d'histoire contemporaine et d'histoire politique, voire éthique, puisque le volume se conclut sur la question du commerce du sang et d'autres organes et des limites qu'on peut leur opposer.

La variété des thèmes et des approches est très grande et le lecteur ne peut que se réjouir de voir évoqués les sacrifices d'animaux dans l'Antiquité ou les vampires, en passant par les sanglantes images mariales au Moyen Âge, la découverte de la circulation exacte du sang, les tableaux de Delacroix ou les cellules souches; mais le recenseur, hélas, ne peut passer en revue tous les articles malgré l'intérêt de chacun et en privilégier certains au nom de ses propres compétences, forcément limitées, ne rendrait pas justice au caractère multidisciplinaire et transpériodique qui fait un des atouts de l'ouvrage. On se contentera donc, bien qu'à regret, de donner au moins un aperçu fidèle du contenu du volume, en reproduisant le sommaire.

I. I « Blut in der Antike » : Jiri Janák and Filip Coppens, «Blood in Ancient Egyptian Religion »; Hana Vymazalová, «Blood in Ancient Egyptian Medical Texts»; Bruno Bleckman «Die Kritik des blutigen Opfers in der Spätantike »;

II. «Blut und Bildgeschichte»: Falk Wiesmann, «Hostienfrevel. Die bildmediale Verbreitung eines antijüdischen Stereotyps»; Wolfgang Treue, «Das Blutmotiv in der antijüdischen Diskurs vom Mittelalter bis in die Moderne - Texte, Bilder, Interpretationen »; Jan Royt, "Mystikerkruzifixe und blutende Marienbilder »; Hans Körner, «Delacroix, Blutsee» Blut und Farbe in der Malerei»; Irmtraut Götz von Olenhusen, "'Blutsauger’: Mediengeschichte des Vampyrismus »;

III. «Blut in der medizinischen Forschung»: Gabriele Franken und Alfons Labisch, «Blut als notwendiger Faktor für Krankheiten - Erythrozyten, Plasmodien, Malaria»; Jürgen Schrader, «Moderne medizinische Bildgebung von Entzündungen »; Robert Pytlik, «Blood and the Stem Cell Concepts»; Michael Andel und Pavel Kraml, «Blut aus nichthämatologischer Sicht ».

Dans la quatrième section, "Blut als Gegenstand der Wissenschaftsgeschichte ", on pourra lire dans l'ordre: Christoph auf der Horst, "Die Sprache des Blutes. Die Entdeckung des Blutkreislaufes zwischen Physiologie und politischer Idee»; Michael Martin, « Blutbilder. Visualisierung in der medizinischen Diagnostik zwischen Bild und Zahl »; Soňa Štrbáňová, «Blood as a Research Object at the Prague Medical Faculties. History Mingled with Politics»; Petr Svobodny, «Die Hämatologie an der Prager medizinischen Fakultät vom Ausgang des 19. bis zur Mitte des 20. Jahrhunderts »; et dans la dernière partie de ce recueil, intitulée "Blut in der Sicht unterschiedlicher Kulturen », on lira Josef Kandert, « Das symbolische Verständnis von Blut im Vergleich aus europäischer und afrikanischer Sicht »; Irena Vaňková, «Blut im tschechischen Weltbild», et Dieter Birnbacher, «Blut- und Organspende. Wie fähig sind die Gründe gegen Kommerzialisierung?».

Cet ouvrage riche et varié confirme la vivacité de la recherche historique autour du thème du sang, particulièrement active dans le monde germanique depuis par exemple, pour la période médiévale, les travaux de Friedrich Lenhardt et d'Ortrun Riha: les rencontres germano-tchèques dont ce volume rassemble la substance suivent de fait d'assez près la publication de Blood in History and Blood Histories, édité par M. Gadebusch Bondio à Florence en 2005. Mais leur principal intérêt à mes yeux est la vision plus globale proposée ici sur la question ô combien polysémique du sang dans un grand 
nombre de contextes tant spatiaux et sociaux que chronologiques. En satisfaisant les curiosités et les sensibilités les plus multiples, ce recueil semble donc avoir parfaitement atteint le but esquissé dans l'introduction par Jiří Pešek : montrer que le thème du sang, ce phénomène biologique en soi déjà si complexe et avec lequel les hommes entretiennent depuis la nuit des temps un rapport ambivalent, peut fédérer les intérêts et les approches de spécialistes aussi divers que les médecins, les théologiens, les politologues, les chimistes, les juristes, les historiens de toutes périodes et les historiens de l'art, les économistes ou les spécialistes de l'histoire du judaïsme, ou encore les égyptologues, les africanistes et les anthropologues. Mais s'il est possible d'établir des ponts, de mettre au jour des continuités, spatiales ou chronologiques, par exemple à propos du sang comme facteur d'exclusion ou de jugement, ce volume n'a aucune prétention à la synthèse, comme le dit lui-même Jiří Pešek p. 8, qui y voit bien plutôt une incitation à continuer de développer des recherches dans les directions si variées qu'il a tracées; de ce point de vue, le pari est parfaitement réussi, et on soulignera pour finir que l'effort d'illustration, lui aussi riche et divers, puisqu'on trouve reproduites aussi bien des miniatures médiévales que des photos du Bal des Vampires de Polanski, joue un rôle non négligeable dans l'attraction exercée par cet ouvrage sur tout lecteur curieux de s'ouvrir à une très large palette de lieux, de temps, et d'approches, que relie ici, c'est le mot, un magnifique fil rouge.

\section{INDEX}

Thèmes : Histoire de la culture, Histoire des idées

Index chronologique : Ouvrages transpériodiques

\section{AUTEUR}

\section{LAURENCE MOULINIER-BROGI}

Université Lumière-Lyon 2 